RAE-IC, Revista de la Asociación Española de Investigación de la Comunicación vol. 8, núm. 16 (2021), 289-312 ISSN 2341-2690

Recibido el 8 de junio de 2021 DOI: https://doi.org/10.24137/raeic.8.16.14 Aceptado el 14 de septiembre de 2021

\title{
La Comunicación como fundamento de la reputación organizacional
} Communication as the foundation of organizational reputation

\author{
Vila Núñez, María Luisa \\ zaluvin@gmail.com
}

\section{Forma de citar este artículo:}

Vila Núñez, M. L. (2021). La comunicación como fundamento de la reputación organizacional. RAE-IC, Revista de la Asociación Española de Investigación de la Comunicación, 8(16), 289-312. https://doi.org/10.24137/raeic.8.16.14

\section{Resumen:}

A pesar de su aureola de celebridad y de su expansión en las organizaciones, la Comunicación de fuente presenta carestías y rémoras que hacen que su trascendencia sea más simbólica que real. Desde los ejes de la ética y la profesionalización, la gestión comunicativa en las fuentes organizacionales requiere afrontar responsablemente sus retos e inquietudes, salvando obstáculos, con arreglo a un pertinente ordenamiento normativo, que le posibilite avanzar y fraguar su propia personalidad sin ataduras, y así, poder proyectar toda su capacidad y legitimarse en sus campos de actuación. En esta progresión, una pieza vital es su demarcación académica, normalizada como grado universitario, que avale y dignifique su desempeño profesional, paliando el intrusismo y salvaguardando su deontología. Resulta inexcusable el compromiso participado y concertado de todos los activos, para que la Comunicación de fuente Organizacional 
logre una justa, auténtica y apropiada valorización y validación. Se despliega una metodología cualitativa de observación documental, con el objetivo de aportar planteamientos en aras de la dignificación de la Comunicación de fuente.

Palabras clave: Comunicación de fuente, ética, legitimación, dignificación profesional, valorización real.

\section{Abstract:}

Despite its aura of celebrity and its expansion in organizations, Source Communication presents shortages and hindrances that make its significance more symbolic than real. From the axes of ethics and professionalization, communicative management in organizational sources requires responsibly facing their challenges and concerns, overcoming obstacles, in accordance with a pertinent regulatory order, which enables them to advance and forge their own personality without ties, and thus, to be able to project all their capacity and legitimize themselves in their fields of action. In this progression, a vital piece is their academic demarcation, standardized as a university degree, which endorses and dignifies their professional performance, alleviating intrusion and safeguarding their deontology. The participation and concerted commitment of all the assets is inexcusable, so that the Communication from an Organizational source achieves a fair, authentic and appropriate assessment and validation. A qualitative methodology of documentary observation is deployed, with the aim of providing proposals for the sake of dignifying Source Communication.

Keywords: Source communication, ethics, legitimation, professional dignity, real appreciation.

\section{INTRODUCCIÓN}

La planificación global de la comunicación, la estrategia o la gestión comunicativa integral son piezas indispensables para la vida de la organización en la sociedad. Pero estos insumos comunicativos organizacionales deben cimentarse y sustanciarse en los 
principios de la ética y de la profesionalización, para que en sí, la Comunicación de fuente sea una comunicación legítima, que verdaderamente se constituya como fundamento de la reputación y acreditación de la existencia de la organización.

La Comunicación de fuente Organizacional tiene que desprenderse de lastres, de rémoras, expeler distorsiones, que le impiden desplegar con independencia su potencial en el campo de aplicación práctica y como disciplina académica. Necesita sus normas, sus regulaciones, sus criterios, sus métodos, sus especificidades, que le permitan ir hacia adelante y no quedar desfasada, supeditada o estancada, a modo de foto fija, en los diferentes espacios de desarrollo, como el laboral, el sindical, el profesional, el organizacional, el de colegiación, el deontológico, el legal, el jurídico, el gubernamental, el de la formación, el teórico o el investigador.

La actividad comunicativa en las fuentes organizacionales requiere estímulos e impulsos que potencien su asentamiento competencial en la teoría y en la praxis, donde, actualmente, y a pesar de su fama, popularización, significación y expansión, realmente, más bien está invisibilizada y discriminada, en una especie de cajón de sastre, donde casi todo cabe, y adolece de la valorización y del prestigio que otorgan la legitimación, el rigor, el reconocimiento y el respeto.

La relevancia de la Comunicación de fuente es más figurativa y retórica que real. En su camino, a la actividad le sobra la aureola de adulación que la encasilla en un plano ficción. La profesión comunicacional organizacional precisa romper este encorsetamiento e irrumpir en la realidad sin dependencias, con entidad, potestad y garantías propias, mediante planteamientos y avances normativos, formales, que le permitan encarar sus dificultades y solucionar su problemática, mediante la concreción y ordenación de reglamentos y conceptos.

Se trata de un itinerario responsable que la Comunicación de fuente urge emprender para progresar, fructificar y situarse como le corresponde, con una puesta en valor apropiada y legitimada. En las conclusiones de su tesis doctoral, Mạ Luisa Vila Núñez (2012) pone el acento en "unha valoración efectiva e adecuada da actividade comunicativa institucional (...), que faga posible o progreso e consolidación deste labor 
a nivel profesional e social" [una valoración efectiva y adecuada de la actividad comunicativa institucional (...), que haga posible el progreso y consolidación de esta labor a nivel profesional y social] (p. 590).

\section{METODOLOGÍA Y OBJETIVOS}

Por lo que se refiere al enfoque metódico de este artículo, el contexto teórico y el de los aspectos encuestados y escrutados se reconocen de nuevo por la autora para su examen y estudio en el presente trabajo. Este marco metodológico cualitativo se amplía con la exploración y análisis de documentos recabados online. Las reflexiones y valoraciones en torno a la temática expuesta complementan la metodología. Los objetivos primordiales son aportar planteamientos, ideas, contribuir al pensamiento, con la intención de dar un paso más en la validación y dignificación de la Comunicación de fuente Organizacional.

\section{INFORMAR DESDE LA FUENTE COMUNICATIVA}

En esta línea expositiva, consideramos primordial aproximarnos a la tarea de informar desde las fuentes comunicativas organizacionales. Para ello, recogemos observaciones que expone Miguel Ángel Vázquez Burgos (2004, pp. 15-26), bajo los epígrafes “El concepto nuclear de información de fuente" (p.15) y “Consideraciones deontológicas: el mito del periodista traidor" (p. 19).

Argumenta Vázquez (2004, p. 16) que tanto "periodistas" de "medios" como de "gabinetes" "son informadores", pero remarca que "El informador de fuente es aquél que obtiene la información que distribuye de un origen único" (Vázquez, 2004, p. 18), y -apostilla el autor- “(...) esa fuente única es sobradamente conocida por el resto de los actores implicados en el hecho informativo" (Vázquez, 2004, p. 18).

Desde ese ángulo, Vázquez (2004) registra:

Hemos llegado al concepto de información (e informador) de fuente. Postularemos, pues, que información de fuente es aquélla que se facilita con un origen explícito y conocido, y que por lo tanto compromete el prestigio y la opinión de dicha fuente primaria (p. 18). 
En esta coyuntura, Mar de Fontcuberta en el preámbulo que hace del libro de Txema Ramírez (1995, pp. 13-15) enlaza con las tesis de Vázquez Burgos (2004, pp. 15-26) en cuanto a la clarificación y reconocimiento de la identidad de la fuente comunicativa y al comportamiento de respetabilidad, en el que repararemos más adelante. De este modo, Mar de Fontcuberta en el "Prólogo" realizado en Ramírez (1995, p. 15) rubrica:

Una cosa es que existan emisores cuyo objetivo sea transmitir una imagen positiva de sí mismos a la sociedad (hecho que al ser conocido no plantea equívocos) y otra que esa imagen se pretenda conseguir mediante la mentira, la presión o simplemente el chantaje. (Ramírez 1995, p. 15).

Siguiendo esta tendencia, Juan Tomás Frutos y Ana María Marín Conesa (s.f., párrafo 119) cotejan disparidades y trazos semejantes entre los "periodistas" que ejercen en los "medios" y los que ejercen en las "fuentes", porque, según aducen,

Les une una misma profesión y una misma problemática: la de enfrentarse constantemente al dilema de una práctica profesional deontológicamente impecable compatible con los intereses (económicos, político-ideológicos, o ambos a su vez) de las empresas, mediáticas o no, a las que los periodistas prestan sus servicios. Hay que hablar con claridad: sobre los medios pesan muchos intereses, unos intereses que podrían condicionar la tarea de los profesionales. Nada que no suceda con los periodistas que trabajan en esas llamadas "fuentes informativas. (Tomás y Marín, s.f., párrafo 119).

En esta composición, incurrimos en el "Prólogo" de Javier Fernández del Moral en Westphalen, M. H. y Piñuel, J. L. (1993, pp. XI-XX). En este “Prólogo", del Moral habla de “(...) hacer más rigurosa e independiente la comunicación al servicio de la sociedad, ya se aplique en el ámbito de los medios de comunicación o se aplique en el ámbito de las fuentes (empresas o instituciones)" (Westphalen, M. H. y Piñuel, J. L., 1993, p. XIV).

Se conjugan los valores de profesionalización y ética que procuramos en la ordenación y reglamentación de la comunicación en las fuentes organizacionales. 


\section{DEFINICIÓN PROPIA Y VALORIZACIÓN FRENTE AL INTRUSISMO}

Para evolucionar y afirmarse, la Comunicación de fuente Organizacional precisa demarcación y definición en el ámbito académico, con una titulación de grado propia, concluyente e inherente a esta materia formativa, reglamentada en las universidades de España con enseñanzas de comunicación e información, que cualifique, habilite y confiera las credenciales adecuadas y privativas a los titulados para su desempeño profesional.

Este análisis sobre la delimitación en el campo de la graduación lo mantiene Juan Manuel Mora ${ }^{1}$ (2009), que describe:

Sería deseable que esta tarea de diferenciación se notase incluso en la formación universitaria. Es decir, que las relaciones públicas o la comunicación institucional fuesen un título específico, una especialización distinta del periodismo, de la publicidad y de la ficción; aunque, como es natural, todas las especialidades compartan algunas materias (p. 22)

Ahondando en esta cuestión, Mora (2009) preconiza que "Un título universitario diferencial sería un paso significativo en la maduración de la profesión" (p. 22).

Al enfocar esta alegación de una cabecera explícita y determinante en Comunicación de fuente Organizacional, nos internamos en la web de la Asociación Española de Universidades con Titulaciones de Información y Comunicación (ATIC) (s.f.), que en la sección "miembros" (s.f.), enumera treinta y ocho centros, que nos conducen a sus respectivos sitios webs. En estos, verificamos que solo la Universitat Autònoma de Barcelona, en la Facultat de Ciències de la Comunicació (2020), cuenta con un grado particularizado expresamente en Comunicación de fuente, bajo la denominación "Grado de Comunicación de las Organizaciones" (2020), como se puede observar en el enlace ${ }^{2}$ recuperado el 6 de diciembre de 2020.

\footnotetext{
${ }^{1}$ En esta articulación, Mora (2009, p. 17) rotula que “Las facultades de comunicación están haciendo un esfuerzo para entender el nuevo contexto y para encontrar el lugar de las profesiones comunicativas".

2 https://www.uab.cat/web/estudiar/llistat-de-graus/informacio-general-1216708251447.html?param1=1345780068935
} 
La circunscripción académica específica e inequívoca de la Comunicación de fuente Organizacional, con una denominación normalizada en la esfera universitaria, sería una buena fórmula -entre otras- para paliar el intrusismo que padece la profesión y favorecer su validación y aprecio en el terreno de la enseñanza y el estudio, así como en el laboral, el organizacional o el social.

En consonancia con este enfoque se sitúa Fernando Martín Martín (2006), que distingue “(...) esa cada vez más emergente vía profesional que es la de conseguir gestionar la Comunicación interna y externa de una organización" (p. 18). En este punto, Martín (2006, p. 18) también sostiene que "es importante que las Universidades, Asociaciones y los Profesionales de la Comunicación (...) lleguemos a unirnos (...)”. Y agrega, “(...) sin olvidar nuestra constante formación por medio de carreras universitarias con itinerarios diferenciados para cada una de las áreas comunicativas, (...)" (Martín, 2006, p. 18). En su opinión, "Así llegaremos a ser más respetados por nuestras organizaciones" (Martín, 2006, p. 19).

Al indagar en contenidos para detallar una titulación y para calibrar el desafío de enfrentar el intrusismo laboral, nos hacemos eco de informaciones, un comunicado y un documento que evidencian obstáculos y desventajas, que tiene que encarar en su trayectoria, la Comunicación de fuente. Informaciones, comunicado y documento que también reflejan que se están produciendo algunos avances -aunque todavía insuficientes-, con diversos planteamientos que vienen de la mano de entidades del sector, como analizamos a continuación.

Primeramente, identificamos una información del Colegio Profesional de Periodistas de Andalucía (CPPA), sobre el foro donde el Colegio andaluz anuncia el "Compromiso Público por el Empleo y la Profesión Periodística", según muestra el CPPA, a través del link $^{3}$, recuperado el 6 de mayo de 2020, y que también da acceso al documento en su integridad. Recopilamos estos párrafos:

${ }^{3}$ https://periodistasandalucia.es/todos-los-colegios-periodistas-espana-los-sindicatos-la-fape-asociaciones-le-prensa-centrosuniversitarios-respaldan-compromiso-publico-empleo-la-profesion-periodistica/ 
Todos los Colegios de Periodistas de España respaldan el Compromiso Público por el Empleo y la Profesión Periodística presentado por el Colegio de Periodistas de Andalucía. 5 marzo, 2017/0 Comentarios/en Noticias, Novedades /

Esta iniciativa persigue que las administraciones locales, provinciales y autonómicas contraten a titulados en Periodismo y Comunicación Audiovisual para la gestión de la comunicación y creen puestos específicos para la realización de estas funciones.

El Colegio Profesional de Periodistas de Andalucía (CPPA) ha presentado este sábado 4 de marzo en Sevilla, el acuerdo Compromiso Público por el Empleo y la Profesión Periodística, una iniciativa que pretende comprometer con el periodismo a todas las administraciones, en todos los territorios y en los distintos niveles de organización, tanto local como provincial y autonómico, dando ejemplo al resto de la sociedad. (...).

Descarga el texto íntegro del Compromiso Público por el Empleo y la Profesión Periodística (CPPA, 5 de marzo de 2017).

Otra información que reflejamos, que además hace referencia al mencionado "Compromiso", es de la Asociación Española de Universidades con Titulaciones de Información y Comunicación (ATIC), de acuerdo con el vínculo ${ }^{4}$, recuperado el 30 de junio de 2020, del que extraemos estas partes:

Los Colegios de Periodistas defienden en la Universidad la exigencia de la titulación para el ejercicio profesional

El I Foro Colegios de Periodistas - Universidad destaca el papel de los Colegios en la lucha contra el intrusismo profesional.

Madrid, 22 de marzo de 2017.- Los Colegios de Periodistas han defendido hoy en la Facultad de Ciencias de la Información de la Universidad Complutense la exigencia de la titulación para el ejercicio profesional. La lucha contra el intrusismo ha centrado el debate que se ha celebrado hoy en el marco del I Foro Colegios de PeriodistasUniversidad, organizado por los Colegios de Periodistas y la ATIC (Asociación de Universidades con Titulaciones en Información y Comunicación), con la colaboración de

${ }^{4}$ http://titulaciones-atic.com/los-colegios-de-periodistas-defienden-en-la-universidad-la-exigencia-de-la-titulacion-para-elejercicio-profesional/ 
la FAPE (Federación de Asociaciones de Periodistas de España). (...) (ATIC, 22 de marzo de 2017).

Esta información la publica, asimismo, la edición online del diario La Vanguardia. Se trata de una noticia que recoge de Europa Press, con fecha del 22 de marzo de 2017, y recuperada el 6 de marzo de $2020^{5}$ extractamos las siguientes líneas:

Colegios de Periodistas defienden la exigencia de la titulación para el ejercicio profesional.

Los Colegios de Periodistas han defendido este miércoles 22 de marzo la exigencia de la titulación para el ejercicio profesional, en el marco de un debate sobre la lucha contra el intrusismo celebrado en la Facultad de Ciencias de la Información de la Universidad Complutense de Madrid (UCM).

REDACCIÓN 22/03/2017 14:09 MADRID, 22 (EUROPA PRESS)

(...) Según ha informado en un comunicado el Colegio de Periodistas de La Rioja, el encuentro ha tenido lugar en el marco del I Foro Colegios de Periodistas-Universidad, organizado por los Colegios de Periodistas y la Asociación de Universidades con Titulaciones en Información y Comunicación (ATIC), con la colaboración de la Federación de Asociaciones de Periodistas de España (FAPE). (...) (Redacción, Europa Press, 22 de marzo de 2017).

En esta serie, relacionamos la Red de Colegios Profesionales de Periodistas que, el 9 de marzo de 2020, difunde una noticia sobre el intrusismo, recuperada el 1 de julio de $2020^{6}$ mostramos estos fragmentos:

La Red de Colegios Profesionales de Periodistas considera que las bases de la oferta de empleo de técnico de Comunicación en Medialab Prado fomentan el intrusismo

By: Colegiosperiodistas Category: Actualidad

\footnotetext{
${ }^{5}$ https://www.lavanguardia.com/vida/20170322/421094572892/colegios-de-periodistas-defienden-la-exigencia-de-la-titulacionpara-el-ejercicio-profesional.html

${ }^{6} \mathrm{https}$ ://www.colegiosperiodistas.es/la-red-de-colegios-profesionales-de-periodistas-considera-que-las-bases-de-la-oferta-deempleo-de-tecnico-de-comunicacion-en-medialab-prado-fomentan-el-intrusismo/
} 
La Red de Colegios Profesionales de Periodistas muestra su disconformidad con las bases de la oferta de empleo 'Técnico gestión de comunicación en el programa de educación de Medialab Prado', hecha pública a través de la web de la empresa municipal dedicada a la gestión cultural, turística y de espacios y eventos 'Madrid Destino'. En dichas bases se explican claramente las funciones de este puesto, que en su gran mayoría tienen una relación directa con el periodismo y la comunicación, pero a la hora enumerar los requisitos no menciona explícitamente la necesidad de que los candidatos estén en posesión de la licenciatura o grado en Periodismo o en Comunicación Audiovisual. (...).

La Red de Colegios Profesionales de Periodistas considera que las administraciones públicas deben dar ejemplo en la lucha contra el intrusismo laboral y adquirir el compromiso de que para que el desempeño de las funciones de información y/o comunicación propias del ejercicio del periodismo, a través de los gabinetes de prensa o direcciones de comunicación, incluido cualquier medio de titularidad pública, la persona que realice dichas funciones cuente con la titulación universitaria oficial correspondiente a la licenciatura o grado en Periodismo o en Comunicación Audiovisual (Red de Colegios Profesionales de Periodistas, 9 de marzo de 2020).

Enunciamos ahora una noticia reseñada el 11 de febrero de 2019, en la web del Colexio Profesional de Xornalistas de Galicia (CPXG), en el enlace ${ }^{7}$, recuperado el 8 de mayo de 2020 y que alberga una información de la Red de Colegios Profesionales de Periodistas, con este titular y esta fecha: "A Rede de Colexios de Xornalistas defende ante a ATIC os estudos universitarios como requisito para o exercicio profesional. Luns, 11 de febreiro de 2019. (...)." [La Red de Colegios de Periodistas defiende ante la ATIC los estudios universitarios como requisito para el ejercicio profesional. Lunes, 11 de febrero de 2019. (...).].

A continuación, referimos un comunicado de la Agrupación de Periodistas de UGT (AGPUGT) en el link ${ }^{8}$ recuperado el 6 de marzo de 2020, que también explana la demanda de

\footnotetext{
${ }^{7}$ http://xornalistas.gal/novas-eventos/novas/a-rede-de-colexios-de-xornalistas-defende-ante-a-atic-os-estudos-universitarioscomo-requisito-para-o-exercicio-profesional/

${ }^{8} \mathrm{https}$ ://www.fesmcugt.org/2019/10/23/ugt-pide-a-la-femp-que-contraten-a-licenciados-en-periodismo-para-sus-medios-ygabinetes-de-comunicacion/
} 
la titulación en Periodismo, así como el atranco que supone el intrusismo para la función comunicativa profesional institucional. Indicamos estos puntos:

UGT pide a la FEMP que contraten a licenciados en periodismo para sus medios y gabinetes de comunicación

$23 / 10 / 2019$

La Agrupación de Periodistas de UGT (AGP-UGT) solicita a la Federación Española de Municipios y Provincias (FEMP) que haga una recomendación a sus integrantes para que contraten a licenciados en periodismo en todos los medios y gabinetes de comunicación que existen en nuestro país de titularidad local.

Con esta petición a la FEMP -que tiene por socios a Ayuntamientos, Diputaciones, Consejos y Cabildos Insulares, que suman más de 7.400 organismos locales en España-, la AGP-UGT quiere fomentar el empleo entre los licenciados de periodismo y evitar el intrusismo profesional que afecta a este sector. (...) (AGP-UGT, 23 de octubre de 2019).

En esta vertiente, apuntamos una síntesis de una noticia de la Federación de Asociaciones de Periodistas de España (FAPE) (22 junio, 2019): "La FAPE solo admitirá a profesionales titulados. 22 junio, 2019. (...). La FAPE admitirá como nuevos socios, únicamente, a profesionales licenciados en Periodismo, Comunicación o Comunicación Audiovisual. (...).", recuperada el 6 de marzo de $2020^{9}$.

Esta resolución de la FAPE también es divulgada por Eldiario.es, en una noticia de Teguayco Pinto, con fecha del 6 de julio de 2019, titulada “¿Debe un periodista tener la carrera de Periodismo?", y recuperada el 6 de marzo de $2020^{10}$. Esquematizamos los consecutivos párrafos:

¿Debe un periodista tener la carrera de Periodismo?

La Federación de Periodistas ha anunciado que no admitirá a quien no tenga el título, ha levantado críticas en algunos sectores y ha provocado que la Asociación Española de Comunicación Científica se marche de la federación

\footnotetext{
${ }^{9}$ http://fape.es/la-fape-solo-admitira-a-profesionales-titulados/

${ }^{10} \mathrm{https}$ ://www.eldiario.es/sociedad/periodismo_0_917258994.html
} 
"Es una decisión anacrónica que atenta contra del futuro de la profesión y cierra los ojos ante la realidad", afirma, Antonio Calvo, presidente de la AECC. (...).

Teguayco Pinto

$06 / 07 / 2019-21: 44 h$

El pasado 22 de junio, la Federación de Asociaciones de Periodistas de España (FAPE), la primera organización profesional de periodistas a nivel nacional y que cuenta con más de 19.000 asociados, decidió que no admitiría a quienes no estén en posesión del título de periodismo, independientemente de si están ejerciendo como tales. La decisión, que encierra un debate antiguo dentro de la profesión, ha levantado críticas en algunos sectores y ha provocado que la Asociación Española de Comunicación Científica (AECC) se desvincule de la federación. (...).

El objetivo de esta medida, según declara a eldiario.es el presidente de la Federación, Nemesio Rodríguez, es "darle valor al título de periodismo y tratar el problema del intrusismo". (...).

Sin embargo, la decisión ha levantado críticas en algunos sectores, especialmente entre los periodistas y comunicadores científicos, representados por la AECC y que provienen mayoritariamente de otras titulaciones. (...).

La decisión también va en la línea de los colegios profesionales de periodismo, que siempre se han mostrado contrarios a la entrada de no titulados en el sector. "Exigir la colegiación para ejercer la profesión sería lo más recomendable, pero es casi una utopía y ahora mismo nuestra prioridad es intentar evitar al máximo el intrusismo", asegura a eldiario.es Xavier Puig, portavoz del Colegio de Periodistas de Cataluña, uno de los nueve colegios de este tipo que existen en España y que agrupan a unos 7.000 colegiados. (...).

El debate sobre la formación en periodismo

El debate también afecta de lleno a la manera de abordar la formación de los periodistas. Mientras que algunos profesionales creen que el grado es la única titulación que ofrece la formación necesaria, otros consideran que éste no tiene porqué ser el único camino para conseguir dicha formación y algunos incluso ponen en duda la utilidad de la carrera a la hora de formar futuros profesionales. 
"Nosotros siempre hemos exigido la titulación", afirma el portavoz del Colegio de Periodistas de Cataluña, y especifica que "no cuentan ni los máster, ni los posgrados porque consideramos que estos títulos no proporcionan los mismos conocimientos que una licenciatura". Desde la FAPE, Rodríguez asegura que aún no han cerrado la puerta a los que tienen un máster de periodismo, pero provienen de otras titulaciones, "lo que no quiere decir que no se cierre más adelante". (...) (Pinto, 6 de julio de 2019).

Mediante la exploración, se constata la reclamación de las titulaciones universitarias regladas en España en las áreas de la información y la comunicación, para la ejecución profesional, y de forma más singularizada, el requerimiento de estos títulos universitarios, para ejercer, las atribuciones profesionales que confieren, en los departamentos de comunicación de las "administraciones".

Esta exigencia de los referidos títulos como credenciales para el cometido profesional y, particularmente, para certificar el desarrollo profesionalizado de la comunicación en las fuentes institucionales, se percibe como base para prevenir y apartarse del intrusismo en la profesión comunicativa de fuente.

Con el chequeo del conjunto de esta línea argumental se confirman ciertas mejoras -cuya importancia y beneficio reconocemos, junto con otras que también se van dando-, pero que resultan escasas, exiguas, ya que también se exteriorizan y comprueban determinados impedimentos, carencias y sujeciones, que maniatan y embrollan la evolución y legitimación de la labor comunicativa en las fuentes organizacionales. Entre estos, el compulsado intrusismo profesional, que consideramos que es imprescindible y esencial rectificar en aras del progreso, la estima y autonomía profesional de esta disciplina comunicativa. Asimismo, se contrasta la intrascendente inclusión en los centros académicos en España de un título universitario de grado claro, preciso y tipificado en Comunicación de fuente Organizacional.

Sigue siendo indispensable e imperioso suprimir barreras y trabas que ponen freno y entorpecen el auténtico, profesionalizado y reglamentario ejercicio, así como la valorización académica y profesional apta y conveniente de esta modalidad 
comunicativa de fuente, que defiende su potestad a través de un marco normativo garantista en todos sus emplazamientos

\section{ACREDITAR Y DIGNIFICAR EL DESEMPEÑO PROFESIONAL}

Vertebrando las indagaciones, apremia poner de relieve que la aprobación e implantación en las universidades del título de grado propio y terminante en Comunicación de fuente Organizacional, que venimos auscultando, es un pilar esencial para la configuración de los departamentos de comunicación profesionalizados y directivos en las entidades organizacionales.

Como puntal ético-profesional, las propias organizaciones deberían contribuir a asentar esta titulación e identificación acreditativa singular de Comunicación Organizacional, junto con la de Dirección o Gabinete de Comunicación, en todo su engranaje y, como mínimo, deberían contar y formalizar, por lo menos, el requisito de titulados universitarios en Periodismo, en todos los niveles jerárquicos de la estructura orgánica comunicativa, demarcación, según la Asociación de Directivos de Comunicación (Dircom) (2018), con "Recursos humanos al alza. (...), en todos los tipos de empresas, (...)" (p. 28), Quinta Edición de El Estado de la Comunicación en España.

Es evidente que no resulta ético contratar a periodistas titulados para ocupar los puestos técnicos del Gabinete o Dirección de Comunicación, mientras, al mismo tiempo, se contrata a titulados de otras profesiones para los cometidos o posiciones directivas de máxima responsabilidad del Gabinete o Dirección de Comunicación, o para los cargos comunicativos orgánicos, que muchas veces se designan bajo la desvirtuada diversidad denominativa de categorías profesionales y departamentos, en la que se enmascaran y eslabonan direcciones, áreas, gabinetes, jefaturas, coordinaciones o secretarías de comunicación, etc., para la interlocución y gestión comunicativa, en conexión directa con los altos representantes de la organización.

De este modo, relegan de esta función profesional a los y a las titulados/as en las universidades en Comunicación de fuente Organizacional o en Periodismo, con una preparación y una cualificación profesionales apropiadas, en la actualidad, a ese 
desempeño. Desde luego, no contribuye a la dignificación de la profesión comunicativa de fuente, ni a la lucha contra la precarización que la acucia.

En este punto, recabamos de nuevo la noticia en Eldiario.es, “¿Debe un periodista tener la carrera de Periodismo?", recuperada el 6 de marzo de $2020^{11}$ y firmada por Teguayco Pinto, con fecha 6 de julio de 2019, para incidir en la parte de las declaraciones a Eldiario.es de "Xavier Puig, portavoz del Colegio de Periodistas de Cataluña":

(...) asegura a eldiario.es Xavier Puig, portavoz del Colegio de Periodistas de Cataluña, uno de los nueve colegios de este tipo que existen en España y que agrupan a unos 7.000 colegiados. (...).

"Nosotros siempre hemos exigido la titulación", afirma el portavoz del Colegio de Periodistas de Cataluña, y especifica que "no cuentan ni los máster, ni los posgrados porque consideramos que estos títulos no proporcionan los mismos conocimientos que una licenciatura". (...) (Pinto, 6 de julio de 2019).

Desde este vértice, se muestran ilustrativos aspectos de la encuesta de la tesis doctoral de Luisa Vila (2012), en la división sobre la "Formación" (Vila Núñez, 2012, pp. 490495). Vila (2012), al sondear la "Titulación académica da persoa responsable do gabinete de comunicación" [Titulación académica de la persona responsable del gabinete de comunicación] (pp. 490-492), evidencia “(...) un intrusismo profesional no exercicio da comunicación institucional nos concellos galegos" [(...) un intrusismo profesional en el ejercicio de la comunicación institucional en los ayuntamientos gallegos] (Vila, 2012, p. 491).

En otro segmento, Vila Núñez (2012, pp. 493-494) pulsa la necesidad y "relevancia de que os responsables de comunicación dos concellos posúan unha formación académica específica en comunicación institucional" [relevancia de que los responsables de comunicación de los ayuntamientos posean una formación académica específica en comunicación institucional] (Vila, 2012, p. 493), observando “(...) a transcendencia dunha ensinanza definida e específica en comunicación institucional de cara ao exercicio

\footnotetext{
${ }^{11}$ https://www.eldiario.es/sociedad/periodismo_0_917258994.html
} 
práctico desta especialidade profesional, (...)." [(...) la trascendencia de una enseñanza definida y específica en comunicación institucional de cara al ejercicio práctico de esta especialidad profesional, (...).] (Vila, 2012, p. 493).

En este itinerario, reconocemos importante traer de nuevo a colación el citado documento "Compromiso Público por el Empleo y la Profesión Periodística", del Colegio Profesional de Periodistas de Andalucía (CPPA), en este caso, publicado el 15 de abril de $2017^{12}$ y recuperado el 30 de mayo de 2021. Concretamente, acercamos un fragmento que alude a la falta de formalidades, como la de la "titulación", en los puestos comunicativos de los gabinetes institucionales, y que pensamos que debe ser una cláusula sustancial para la realización de una labor de comunicación profesional en las fuentes. De forma textual señala:

(...) A la situación de estos profesionales, hay que sumar la de aquellos otros periodistas que realizan su trabajo en las propias administraciones públicas: los gabinetes de prensa o comunicación, donde sus funciones no siempre están adecuadamente reflejadas, no existen puestos claramente identificados, ni criterios y requisitos nítidos para cumplir tales funciones, a fin de garantizar la independencia del profesional y, en definitiva, el interés de la ciudadanía. Ni siquiera se exige una titulación para ocupar dichos puestos como sí se exige para cualquier otro técnico. (...) (CPPA, 15 de abril de 2017).

Desde esta óptica, Mora (2009) ofrece su punto de vista y puntualiza:

La comunicación institucional necesita definir sus perfiles, entender las semejanzas y las diferencias con otras profesiones fronterizas, como el periodismo y la publicidad. (...). Para diferenciarse hace falta definir las tareas propias, las prácticas profesionales ordinarias, los compromisos éticos, los principios inspiradores, los resultados que un profesional puede ofrecer a una institución. (p. 22)

En estas introspecciones se confirma que la Comunicación de fuente presenta una carestía de concreciones. Un descubierto que está instalado en su misma concepción y

\footnotetext{
${ }^{12}$ https://periodistasandalucia.es/compromiso-para-el-empleo-de-la-profesion-periodistica/
} 
al que se suman pasivos exógenos, impregnando y limitando la edificación acreditada y profesionalizada de su arquitectura, pedagógica y experiencial.

Desde este eje, la disciplina comunicativa organizacional reivindica y necesita condiciones laborales y carácter profesional que promuevan su dignificación y, así, poder expresarse e impulsarse con solvencia.

En el contexto de la profesionalización que confiere la cualificación pertinente se emplaza Lois Celeiro (2000, p. 43), cuando se refiere a los cometidos comunicativos en las organizaciones y marca que deben ser llevados a cabo "por executivos de comunicación que han de posuír autoridade e prestixio, ademáis de estaren avalados por una sólida formación especializada que lles permitirá desenvolver adecuadamente estas funcións" [por ejecutivos de comunicación que han de poseer autoridad y prestigio, además de estar avalados por una sólida formación especializada que les permitirá desarrollar adecuadamente estas funciones].

Con el foco puesto en el rigor, Txema Ramírez (1995) refrenda el debido fondo profesional del quehacer comunicativo:

La comunicación es una herramienta que no admite frivolidades. O se gestiona con profesionalidad y delicadeza, o se paga muy caro, carísimo. Esta cuestión hay que dejarla clara desde el primer momento: la comunicación es un medio, nunca un fin. Se trata de un utensilio increíblemente eficaz cuando se administra inteligentemente, con prudencia. Sin conservantes, aditivos o colorantes. Sin adulteraciones (p. 19).

En la secuencia de la ocupación profesional y digna de la Comunicación de fuente Fernando Martín (2006,) incorpora otros carices, y pormenoriza: “(...) que cumplamos con máxima transparencia, eficacia y veracidad nuestra función, comunicativa y formativa apoyándola en la aplicación directa de concretos Códigos ético-deontológicos y profesionales" (p. 18).

Desde las premisas ética y de profesionalización, la Comunicación de fuente llama a fomentar la construcción de su propia idiosincrasia, como garantía de su gestión, de su deontología, de su reconocimiento, de su prestigio y de su certificación como ciencia, 
como materia, teórica y práctica. La concertación sistematizada y universalizada de sus condiciones y sus atributos singulares, preceptuados en todos los campos de extensión -como el formativo, el profesional, el deontológico, el de colegiación, el laboral, el organizacional o el normativo-, creemos que constituiría el aval, el amparo y la seguridad inexcusables para futuros profesionales, que quieren prepararse y capacitarse para ello formándose de modo apto, con su titulación y conocimientos reglamentarios.

También representaría un revulsivo, un aliciente, para tantos profesionales titulados en Periodismo en ejercicio en las organizaciones. Y, justamente, contribuiría a la solidez, dignificación y autentificación de la Comunicación de fuente organizacional en la sociedad.

La estipulación de la Comunicación de fuente en todo su armazón y representación interpela a todos los activos, para propiciar un compromiso concordado, serio, consciente y auténtico, que conlleve a su afianzamiento como valor seguro y equilibrado.

\section{RECÍPROCAMENTE ÉTICA, HONESTA, LEAL, CONFIABLE}

La Comunicación de fuente no es algo accesorio, es la propia vida de la organización. Sus planteamientos, sus pasos y sus interacciones fraguan la personalidad organizacional. Se trata de lo que la organización proyecta, construye, manifiesta o calla; piensa, siente o significa globalmente, gestando su identidad y su imagen.

Y esta imagen, planificada y gestionada integral y estratégicamente, debe ser recíprocamente ética, honesta, leal y confiable para la totalidad de los públicos que la forman -verdaderos artífices de la comunicación de la organización-, generando así su salvaguarda de autoridad, renombre, fiabilidad y credibilidad en la existencia en la que se desenvuelve.

Estas consideraciones se derivan de formulaciones como las de Joan Costa (1992). Resalta Costa (1992):

Lo que la empresa hace y lo que dice, o el Actuar y el Comunicar, son los grandes vehículos de la Acción -y en consecuencia, de la imagen pública- (...). Es en el público donde está la imagen, desde donde se interpreta todo lo anterior, y desde donde se experimentan, a través de los hechos, las contradicciones entre el hacer y el decir (p. 167). 
En afinidad, se enmarcan explicaciones de Paul Capriotti (1999). Acentúa el autor que “(...) la imagen corporativa es el resultado de un proceso creativo por parte de los públicos" (Capriotti, 1999, p. 130).

Argumentaciones de José Luis Carrascosa (1992, pp. 44-45) cobran envergadura en este recorrido. Estima Carrascosa (1992, p. 44) que "Cuando una empresa habla, comunica, compromete su palabra y, con ella, su honor, ya que las entidades hablan siempre con solemnidad, institucionalmente". Con este visor, Carrascosa (1992) puntea que "Si la eficacia en la actividad es lo que determina la utilidad de una organización, la ética es lo que configura su verdadero valor añadido" (p. 45).

Desde este prisma, Vázquez Burgos (2004, pp. 15-26) inscribe la ligazón de integridad y de respeto -a la que aludimos inicialmente- entre el profesional que ejerce la comunicación organizacional y sus públicos. Subraya que "Puede, y debe, existir un compromiso del informador de fuente con sus receptores" (Vázquez, 2004, p. 24). En este sentido, Vázquez (2004) añade que “(...) este compromiso ético con el receptor que aquí defendemos se formula mejor en sentido negativo, esto es: no contar mentiras" (p. 24).

Al hilo de estas reflexiones, se deduce que la gestión comunicativa de las relaciones de reciprocidad, de las interactuaciones de la organización en su hábitat, con el objetivo de lograr una imagen reputada y solvente, no admite ni el embuste ni las artimañas. Son incompatibles, porque la comunicación es esencia, no es apariencia, o dicho en palabras de Carrascosa (1992):

La Comunicación Global es, por tanto, una cuestión ÉTICA más que ESTÉTICA. Un planteamiento MORAL, antes que un planteamiento EFICAZ. La Comunicación Global no es solo la coherencia de los discursos: Es la coherencia de los discursos con los actos (p. 243).

En paralelo a estos postulados se orienta José María La Porte (2009), que también realza los componentes éticos como piezas comunicativas medulares, enfatizando que "El paradigma ético implica respetar la verdad, rectificar las decisiones equivocadas, no ocultar lo que los empleados y voluntarios deben saber. Una actuación coherente con 
este principio proporciona al departamento algo que es esencial para su trabajo: credibilidad" (La Porte, 2009, p. 139).

El plan comunicativo ha de fundamentarse en la articulación programática integral de las interacciones y los intercambios conversacionales a través de la confianza mutua, núcleo del equilibrio organizacional, que conduce a la notoriedad y al prestigio público. Según perfila Kenneth D. Makovsky (2001):

Le guste o no a algunos dirigentes, su organización está inmersa en un gran diálogo con muchos públicos. Y algunos de estos públicos surgen de hoy para mañana. El que se trate de un diálogo de sordos o de un diálogo constructivo entre ambas partes depende de cómo se maneje (p. 468).

\section{RESULTADOS Y CONCLUSIONES}

De las propuestas se infiere una estrategia global e integradora de la Comunicación de fuente, comprendida desde las coordenadas de la ética y la profesionalización, gestionada directivamente con rigor, con honestidad y congruencia. Todo ello mediante la planificación de interactividad recíproca, en empatía y lealtad mutua con los públicos, cardinal para forjar la imagen de reputación social de la organización, consistente, confiable, creíble, perdurable.

La Comunicación de fuente debe concebirse, cimentarse y desplegarse profesionalmente en toda su magnitud, amparada académicamente en las universidades de España con una titulación particular y sistematizada de grado, piedra angular y resguardo de su prestigio y deontología como materia académica y experiencial.

Para fraguar y afianzar su propia personalidad, sin dependencias ni obstrucciones, la Comunicación de fuente Organizacional no puede esconderse ni desdibujarse en ningún programa establecido, debe encarar sus desafíos tomando la iniciativa con valentía e inteligencia. Urge movilizarse de forma responsable para superar barreras y afecciones, intrínsecas y extrínsecas, sin pretextos ni dilaciones, para avanzar en todos sus espacios de implantación y lograr su justa valía, como disciplina autónoma, respetuosa y respetada. 
La estipulación y el ordenamiento de la Comunicación de fuente Organizacional, con la potestad y garantías concernientes a la profesionalización, requieren la participación dinámica, comprometida y concertada de los diversos actores, desde las instancias gubernamentales, administrativas y académicas, pasando por las propias organizaciones, hasta los colegios y las asociaciones profesionales sectoriales o los sindicatos, con la mira en la concreción, ajuste y valorización real y objetiva, no figurada, de esta profesión, en toda su amplitud.

La formalización y la legitimación de la Comunicación de fuente como valor estable y armónico se erigen en garantes de sus mandatos éticos y de su rigor profesional, así como de su crédito público, y consecuentemente, del arraigo y de la reputación efectiva de la organización en la sociedad.

\section{REFERENCIAS BIBLIOGRÁFICAS}

Agrupación de Periodistas de UGT (AGP-UGT). (23 de octubre 2019). UGT pide a la FEMP que contraten a licenciados en periodismo para sus medios y gabinetes de comunicación [Comunicado]. Fesmcugt.org. Recuperado de https://cutt.ly/ORKhT8D

Asociación de Directivos de Comunicación (Dircom). (2018). El Estado de la Comunicación en España (Quinta Edición). Recuperado de https://cutt.ly/ZRKhL75

Asociación Española de Universidades con Titulaciones de Información y Comunicación (ATIC). (22 de marzo 2017). Los Colegios de Periodistas defienden en la Universidad la exigencia de la titulación para el ejercicio profesional. El I Foro Colegios de Periodistas Universidad destaca el papel de los Colegios en la lucha contra el intrusismo profesional. Recuperado de https://cutt.ly/YRKhB6H

Asociación Española de Universidades con Titulaciones de Información y Comunicación (ATIC). (s.f.). Recuperado de http://titulaciones-atic.com/

Asociación Española de Universidades con Titulaciones de Información y Comunicación (ATIC). (s.f.). Recuperado de http://titulaciones-atic.com/miembros/ 
Capriotti, P. (1999). Planificación estratégica de la imagen corporativa. Barcelona: Ariel Comunicación.

Carrascosa, J. L. (1992). ComunicACCIÓN. Una comunicación eficaz para el éxito en los negocios. Madrid: CDN, Ciencias de la Dirección.

Celeiro, L. (2000). A comunicación na empresa e na institución. En Álvarez Sousa, A. (Coord.) (2000), Realidade social galega. (Homenaxe a J. L. Sequeiros Tizón) (pp. 3552). Vigo: Ir Indo Edicións.

Colegio Profesional de Periodistas de Andalucía (CPPA). (15 de abril 2017). Compromiso público por el empleo y la profesión periodística. Recuperado de https://cutt.ly/PRKjhDp

Colegio Profesional de Periodistas de Andalucía (CPPA) (5 de marzo 2017). Todos los Colegios de Periodistas de España respaldan el Compromiso Público por el Empleo y la Profesión Periodística presentado por el Colegio de Periodistas de Andalucía. Recuperado de https://cutt.ly/RRKjZIm

Costa, J. (1992). Imagen pública. Una ingeniería social. Madrid: Fundesco.

Federación de Asociaciones de Periodistas de España (FAPE). (22 de junio 2019). La FAPE solo admitirá a profesionales titulados. Recuperado de https://cutt.ly/tRKkpka La Porte, J. M. (2009). Principios de comunicación interna en el tercer sector. En Mora, J. M. (Editor) (2009), 10 ensayos de comunicación institucional (pp. 123-140). Barañáin (Navarra): Ediciones Universidad de Navarra (EUNSA).

Makovsky, K. D. (2001). El poder de la comunicación: La comunicación estratégica. En Pérez González, R. A. (Coord.) (2001), Estrategias de Comunicación (pp. 449-483). Barcelona: Ariel Comunicación.

Martín Martín, F. (2006). Comunicación Empresarial e Institucional. Madrid: Editorial Universitas. 
Mora, J. M. (2009). Introducción. Nuevos desafíos para una profesión centenaria. En Mora, J. M. (Editor) (2009), 10 ensayos de comunicación institucional (pp. 13-27). Barañáin (Navarra): Ediciones Universidad de Navarra (EUNSA).

Pinto, T. (6 de julio de 2019). ¿Debe un periodista tener la carrera de Periodismo? Eldiario.es. Recuperado de https://cutt.ly/WRKkvLg

Ramírez, T. (“Prólogo" de de Fontcuberta, pp. 13-15). (1995). Gabinetes de comunicación. Funciones, disfunciones e incidencia. Barcelona: Bosch Comunicación.

Ramírez, T. (1995). Gabinetes de comunicación. Funciones, disfunciones e incidencia. Barcelona: Bosch Comunicación.

Red de Colegios Profesionales de Periodistas. (11 de febrero 2019). A Rede de Colexios de Xornalistas defende ante a ATIC os estudos universitarios como requisito para $o$ exercicio profesional. Recuperado de https://cutt.ly/FRKkUwL

Red de Colegios Profesionales de Periodistas. (9 de marzo 2020). La Red de Colegios Profesionales de Periodistas considera que las bases de la oferta de empleo de técnico de Comunicación en Medialab Prado fomentan el intrusismo. Recuperado de https://cutt.ly/nRKkPtz

Redacción Europa Press. (Madrid, 22 de marzo de 2017). Colegios de Periodistas defienden la exigencia de la titulación para el ejercicio profesional. Lavanguardia.com. Recuperado de https://cutt.ly/FRKkGcl

Tomás Frutos, J. y Marín Conesa, A. M. (s. f.). Las relaciones con los medios: el funcionamiento de los gabinetes de prensa. Recuperado el 20 de abril de 2020 de https://cutt.ly/PRKkJi7

Universitat Autònoma de Barcelona, Facultat de Ciències de la Comunicació. (2020). Recuperado de https://cutt.ly/VRKIrHt

Universitat Autònoma de Barcelona, Facultat de Ciències de la Comunicació. (2020). Recuperado de https://cutt.ly/qRKluB6 
Vázquez Burgos, M. A. (2004). El profesional de las relaciones externas. Los gabinetes de comunicación desde la perspectiva periodística. Sabadell (Barcelona): Bosch Comunicación.

Vila Núñez, M. L. (2012). A comunicación institucional nos concellos galegos. (Tese de Doutoramento sin publicar). Universidade de Santiago de Compostela, Facultade de Ciencias da Comunicación, Departamento de Ciencias da Comunicación.

Westphalen, M. H. y Piñuel, J. L. (“Prólogo” de Fernández del Moral, J., pp. XI-XX). (1993): La dirección de comunicación. Madrid: Ediciones del Prado. 